\title{
Congestión urbana en Santiago de Cali, un estudio de caso de política pública ${ }^{*}$
}

Urban Congestion in Santiago de Cali, a Case Study of Public Policy

Congestão urbana em Santiago de Cali, um estudo de caso de politica pública

Rafael Vergara Varela ${ }^{* *}$

Jorge Enrique Arias Calderón ${ }^{\star * \star}$

María Eugenia Rodríguez Vásquez ${ }^{* \star *}$

Recibido: 19 de septiembre de 2018

Aprobado: 9 de enero de 2019

Doi: http://dx.doi.org/10.10.12804/revistas.urosario.edu.co/territorios/a.7239

Para citar este artículo:

Vergara Varela, R., Arias Calderón, J. E., Rodríguez Vásquez, M. E. (2020). Congestión urbana en Santiago de Cali, un estudio de caso de política pública. Territorios, (42), 1-29. Doi: http://dx.doi.org/10.10.12804/ revistas.urosario.edu.co/territorios/a.7239

* Las opiniones expresadas en este documento comprometen únicamente a sus autores y no a las entidades involucradas.

** Investigador, Universidad del Valle. Correo electrónico: rafael.pergara@correounivalle.edu. co ORCID: https://orcid. org/0000-0003-0363$751 X$

*** Facultad de Ciencias de la Administración de la Universidad del Valle. Correo electrónico: jorge. arias@correounivalle.edu. co ORCID: https://orcid. org/0000-0001-8602-7068

**** Universidad del Valle. Miembro del equipo de politicas públicas del Departamento Administrativo de Planeación Municipal de Cali. Correo 
Palabras clave

Instituciones, desarrollo urbano en Cali, politicas públicas territoriales, gobernabilidad, gobernanza.

Keywords

Institutions, urban development in Cali, territorial public policies, governability, governance.

Palavras-chave

Instituições, desenvolvimento urbano em Cali, politicas públicas territoriais, governabilidade e governança.

territarias 42

\section{RESUMEN}

El artículo busca analizar y estudiar el problema de congestión en la ciudad de Cali. Para tal fin, se expone un análisis transdisciplinar del desarrollo histórico de la urbe en un contexto de larga duración y luego los planes de ordenamiento del siglo XXI. Finalmente, se presenta el problema actual del tráfico vehicular. En este contexto histórico, los planes, programas y proyectos urbanos han intentado, en el marco de políticas públicas territoriales, definir un modelo de ciudad. Empero, la evidencia muestra que para Cali no hay ningún tipo de articulación entre las políticas territoriales del siglo xx y la forma en que se concibe la urbe en siglo XxI. Por ello, en relación a esta discontinuidad del desarrollo territorial sobresalta el caos de la congestión vehicular que se traduce a su vez en serios problemas de ingobernabilidad institucional como plantea el presente estudio.

\section{ABSTRACT}

The article seeks to study the congestion of the city of Cali. For this a transdisciplinary analysis of the historical development of the municipality is exposed in a context of long duration, to later derive in the ordering plans of the 21 st century, and to present the current traffic problem. In this historical context, urban plans, programs, and projects have tried within the framework of territorial public policies to define a city model. However, the evidence shows in Cali there is no articulation between the territorial policies of the twentieth century and the way the city government conceived it for the 21 st century. Therefore, regarding this territorial discontinuity development, the chaos of vehicular congestion is shocking, which in turn translates into serious problems of institutional ungovernability, as the present study suggests.

\section{RESUMO}

O artigo busca analisar e estudar o problema de congestão na cidade de Cali, para tal fim se expõe uma análise transdisciplinar do desenvolvimento histórico da urbe em um contexto de longa duração, para logo derivar nos planos de ordenamento do século XXI, e apresentar o problema atual do tráfico veicular. Neste contexto histórico, os planos, programas e projetos urbanos têm tentado no marco de políticas públicas territoriais definir um modelo de cidade. No entanto, a evidência mostra para Cali que não há nenhum tipo de articulação entre as políticas territoriais do século XX e a forma em que se concebe a urbe no século XXI. Por isto, em relação a esta descontinuidade do desenvolvimento territorial ressalta o caos da congestão veicular que se traduz à sua vez, em sérios problemas de ingovernabilidade institucional como expõe o presente estudo.

Rafael Vergara Varela, Jorge Enrique Arias Calderón, María Eugenia Rodríguez Vásquez 


\section{Introducción}

Este estudio busca presentar el actual problema de congestión vehicular en Santiago de Cali. Para este objetivo, la pesquisa se orienta en torno a un análisis histórico y documental que permite reconstruir el desarrollo urbano a partir de un diálogo de saberes en función de una construcción social de conocimiento que da cuenta del proceso. Es decir, este artículo responde desde un nivel estratégico de orden transdisciplinar en el que dialogan los objetos de estudio entre lo territorial y los componentes histórico, político, cultural e institucional para describir y definir el modelo de ciudad.

Por lo tanto, este ejercicio académico metodológicamente transciende de lo general a lo particular en sus tres temas: 1) La explicación de los antecedentes urbanos en Colombia y la planeación; 2) El desarrollo urbano-histórico en Cali, y 3 ) Cali y la congestión vehicular. En último lugar se encuentran las conclusiones. Cabe resaltar además que este artículo busca explicar pedagógicamente el origen del problema de la congestión vehicular en Cali al medio académico como también al público en general.

Hoy más que nunca, el proyecto de la globalización ha generado escenarios más urbanos que rurales; Latinoamérica no escapa a esta situación o realidad. Según fuentes del Banco Interamericano de Desarrollo — BID- (2016) se indica que la región hispanoparlante-americana es el segundo continente más urbanizado del mundo, lo que significa que las tendencias en las próximas décadas revelan que los centros urbanos llegarían al 90\% de la población total de cada uno de sus países, lo cual se traduce simultáneamente en serios contratiempos en las agendas de los gobiernos en la solución de los problemas actuales con respecto al acceso de ciertos bienes públicos básicos tales como vivienda, servicios públicos y conectividad.

Ahora bien, en las principales ciudades de Colombia el problema de la congestión vehicular no es un tema menor. Frente a la situación caótica de movilización de un sitio a otro en una urbe se requiere cada vez mayor intervención y coordinación de la institucionalidad pública. Por ejemplo, en las últimas dos décadas, en el país hubo una tendencia que muestra cómo ha crecido el uso del vehículo particular en lugar del transporte público, lo que ocasiona y revela el fenómeno de la congestión en los contextos urbanos (figura 1 ).

Bogotá, Medellín y Cali son las ciudades que más padecen de congestión vehicular dado que al ser urbes-receptoras/ centro-regionales le agregan al problema más parque automotor de sus municipios vecinos por motivos de circulación y pendularidad. Precisamente, el actual caos de movilidad en la ciudad de Cali se hace evidente en todos los sectores del territorio, que genera además externalidades negativas especialmente en los semáforos que se traducen en problemas sociales tan diversos como las ventas ambulantes, los electrónico: maria.rodriguez.vasquez@correounivalle.edu.co ORCID: https://orcid.org/00000002-9060-1277

territarios 42 3 
Figura 1. Tendencia del transporte público y privado (en porcentajes)

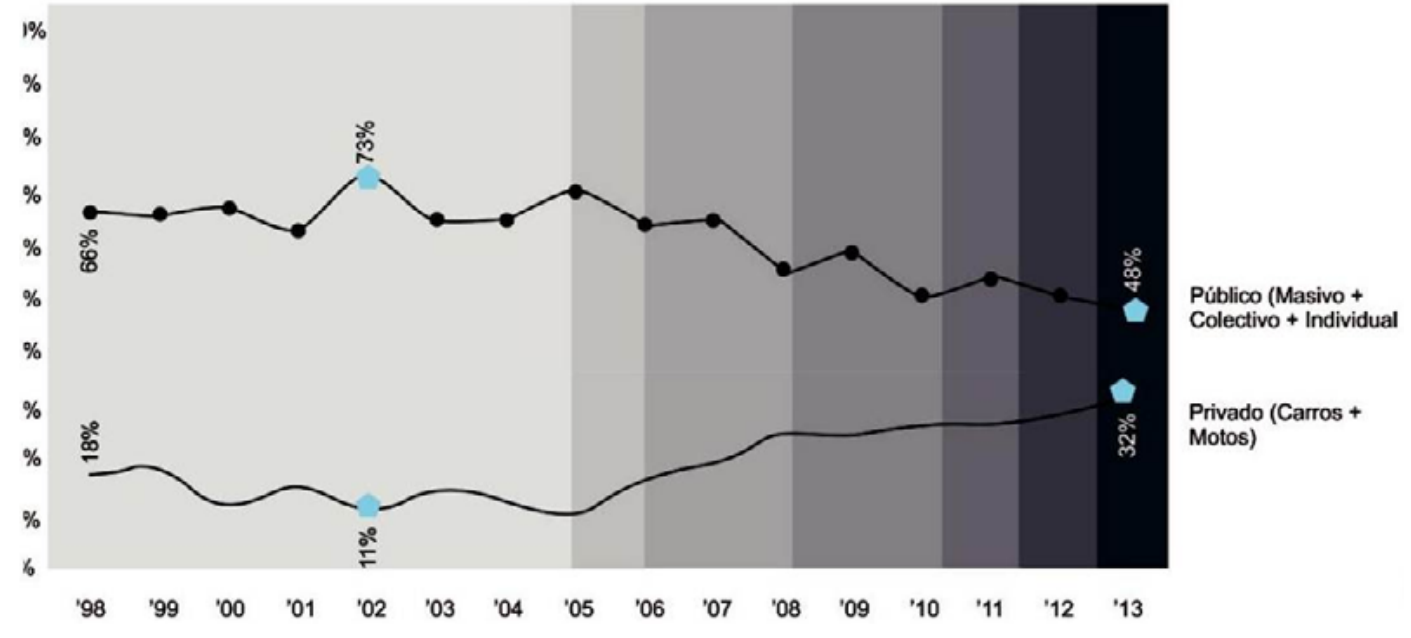

Fuente: Red de ciudades cómo vamos (2015).

espectáculos circenses, la mendicidad, la prostitución y la criminalidad.

Todas estas situaciones han sido un tema recurrente, creciente y desbordado en lo que respecta a la afectación del espacio público, la movilidad y su correlato con la congestión vehicular cotidiana el cual requiere rápidamente de intervención por convertirse en un serio problema que afecta la gobernabilidad territorial y al conjunto de actores de la sociedad. Por esta razón, el objeto de estudio, análisis e investigación de este artículo se concentra en la temática de la congestión en Santiago de Cali como un estudio de caso en política pública el cual explicaremos a continuación.

\section{territarias 42}

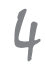

\section{Antecedentes urbanos, institucionales y poblacionales en Colombia}

Se debe destacar que el origen de la primacía urbana en Latinoamérica emerge de una peculiaridad en la historia de su configuración espacial: la traza urbana cuadricular, este esquema aparece desde tiempos coloniales como herencia del legado cultural Español de georeferenciación fundacional alrededor de una plaza principal; su persistencia actual, es fruto de una expresión histórica e institucional de marcar el territorio en términos de legitimidad jurídica, reconocimiento, posesión y dominancia de la empresa o gesta conquistadora bajo títulos de concesión de la corona española, que cinco siglos 
después se resignifica simbólicamente en el contexto republicano del origen histórico-político-institucional de los centros urbanos (Arango, 1993; Robledo \& Rodríguez, 2008).

A partir de este modelo cuadricular fundacional-colonial se desarrollaron las ciudades Latinoamericanas respondiendo al contexto económico local. En Colombia, la orientación de las urbes se conformó también por su referente productivo que en sus orígenes fue agropecuario, extractivo y esclavista (Colmenares, 1987; Melo, 2015 ). Teniendo en cuenta lo anterior, hay otro elemento que explica la tenue conformación del territorio urbano el cual obedeció a "una muy lenta unificación de su espacio político-económico nacional desde el siglo XVI" (Jaramillo \& Cuervo, 1986) que se explicaba por la ausencia de un mercado regional y nacional sólido aunado a la falta de infraestructura de medios de comunicación y conectividad entre las regiones cercanas. Empero, en los albores del siglo Xx, a partir de 1910, nuestro país vio crecer sus principales núcleos urbano-regionales en un franco ascenso dentro de cinco aspectos básicos y esenciales.

En primer lugar, a las cuatro principales urbes (Bogotá, Medellín, Cali y Barranquilla) les llegó muy tardíamente el contexto de "la modernidad capitalista" (Tovar, 1989) explicado por el paradigma economicista basado en el modelo de la producción en cadena; es decir, los esquemas de industrialización y división del trabajo. En segundo lugar, el crecimiento de estas ciudades se explica también por el influjo de las elites político-empresariales que determinaron el ordenamiento del territorio a la zaga del desarrollo industrial y su inversión económica. En tercero, las migraciones rurales motivadas por el factor atrayente del salario remunerado que en el campo no existía (Vásquez, 2001). Cuarto, la migración del campo a la ciudad se explica también por el fenómeno de la violencia político-social que se agravo en la nación después del asesinato de Jorge Eliecer Gaitán en 1948. Al respecto, se debe tener en cuenta además que los migrantes siempre presionan en las ciudades por la solución inmediata de sus demandas (Vergara, 2012).

Como quinto elemento, entre $1930 \mathrm{y}$ 1980 el proceso de industrialización hacia dentro basado en la política estatal denominada Industrialización bajo la égida de la sustitución de importaciones (ISI) ayudó a consolidar e integrar el mercado nacional reforzando regionalmente la primacía del triángulo económico (Bogotá, Medellín y Cali). Con él estas ciudades comienzaron a crecer con mayor rapidez, aunado a un mayor crecimiento de la población y a un acelerado proceso de urbanización.

Un efecto directo del proceso de urbanización es el crecimiento poblacional en municipios de menor tamaño. En los estudios sobre la temática de urbanización siempre se ha indicado que Colombia es un país variado en ciudades dado que concentra menos población en Bogotá, si 
se la compara con otras ciudades capitales del contexto Latinoamericano (tabla 1 ).

Tabla 1. Peso relativo porcentual poblacional de las ciudades en Latinoamérica (1951-2005)

\begin{tabular}{|l|c|c|c|c|c|c|}
\hline \multicolumn{1}{|c|}{ Ciudades } & $\begin{array}{c}\text { Censo } \\
\mathbf{1 9 5 1}\end{array}$ & $\begin{array}{c}\text { Censo } \\
\mathbf{1 9 6 4}\end{array}$ & $\begin{array}{c}\text { Censo } \\
\mathbf{1 9 7 3}\end{array}$ & $\begin{array}{c}\text { Censo } \\
\mathbf{1 9 8 5}\end{array}$ & $\begin{array}{c}\text { Censo } \\
\mathbf{1 9 9 3}\end{array}$ & $\begin{array}{c}\text { Censo } \\
\mathbf{2 0 0 5}\end{array}$ \\
\hline Bogotá & 5.7 & 9.5 & 12.4 & 14.3 & 14.9 & 16.1 \\
\hline Medellin & 2.8 & 4.1 & 5.1 & 5.1 & 4.7 & 5.2 \\
\hline Cali & 2.1 & 3.5 & 4.4 & 4.8 & 5 & 4.8 \\
\hline Barranquilla & 2.4 & 2.8 & 3.2 & 3.2 & 3 & 2.6 \\
\hline Ciudades & 1950 & 1960 & 1970 & 1980 & 1990 & 2000 \\
\hline Buenos Aires & 45.6 & 48.6 & 50.3 & 49.3 & 47.7 & 45.8 \\
\hline Sao Paulo & 17.7 & 17.6 & 19.1 & 21 & 21.7 & 21.8 \\
\hline La Paz & 31.4 & & 31.8 & & 29.6 & 28.4 \\
\hline Santiago & 28.7 & 22.7 & 35.5 & 38.1 & 39.4 & 40.1 \\
\hline Lima & 14.6 & 19.4 & 28 & 30.5 & 31.9 & \\
\hline Mexico D.F. & 17.2 & 16.2 & 22.2 & 24.5 & 22.2 & 22.3 \\
\hline
\end{tabular}

Fuente: elaboración a partir de DANE (2015).

1 Desde el año de 1970, Colombia es un pais más urbano que rural. Hoy Bogotá, Medellín, Cali, Barranquilla y Bucaramanga concentran el $40 \%$ del total de la población urbana en Colombia.

\section{territarias 42}

Al comparar el total porcentual de las ciudades colombianas en relación con las capitales de los otros países latinoamericanos por años y censos, nuestro referente urbano sigue siendo inferior en cantidad poblacional frente a la gran metropolización de Buenos Aires, La Paz y Santiago de Chile. De igual manera, cabe mencionar y también comparar que solo Bogotá como urbe sigue teniendo menos población que São Paulo, Lima y México D. F.

La situación anterior explica que en el país las migraciones no hayan sido muy desbordadas ni tampoco que el desplazamiento sea hacia una sola región. Referenciando el censo de 1993, de 32,8 millones de personas encuestadas, solo un $22 \%$ habían sido migrantes toda su vida. Esto significaba que una de cada cuatro personas vivía en 1993 fuera de su lugar de origen (Martínez \& Rincón, 1997). Como se puede notar también en la tabla 1 , se demuestra que Colombia realmente es un país de ciudades, ya que, al analizar los censos de los años 1951 y 1973, la sumatoria de Medellín, Cali y Barranquilla supera porcentualmente en términos poblacionales a Bogotá, se entendería además que estas urbes han ido creciendo por ser centros relevantes de carácter regional con especial atractivo para la población migrante de las zonas aledañas.

Desde 1973 hasta el último censo (2005) Bogotá, Medellín, Barranquilla y Cali concentran el 30\% de la población en Colombia. ${ }^{1}$ A partir de 1985 la ciudad de Bogotá tiene un ligero incremento (al ser la capital del país el mayor receptor de las regiones). Finalmente, se puede corroborar que Cali frente a la capital colombiana tiene aproximadamente una proporción de uno a tres; es decir, desde 1951 Bogotá en términos poblacionales y espaciales es tres veces mayor en extensión que Cali.

Por su parte, históricamente Cali es receptora de un flujo migratorio relevante durante el último siglo (tablas 2 y 3 ). La migración hacia Cali se ha presentado por aspectos como la violencia política y el 
conflicto armado que determinan el flujo campo-ciudad. Ante esto, los migrantes buscan en las urbes oportunidades de empleo y una mejora del bienestar.

Tabla 2. Crecimiento demográfico de Cali

\begin{tabular}{|c|c|c|c|}
\hline Año & Total & Año & Total \\
\hline 1912 & 27747 & 1985 & 1429026 \\
\hline 1918 & 45525 & 1993 & 1801820 \\
\hline 1938 & 101883 & 2002 & 2038583 \\
\hline 1951 & 284186 & 2009 & 2219633 \\
\hline 1964 & 637929 & 2015 & 2369829 \\
\hline 1973 & 991549 & 2018 & 2445659 \\
\hline
\end{tabular}

Fuente: DAPM (2015).

Como se evidencia en la tabla 2 , en los últimos 106 años (1912-2018), la población de Cali ha aumentado de forma importante. $\mathrm{Al}$ hacer una clasificación en relación al desarrollo urbano y en el contexto de este trabajo se encuentra que entre 1912 y 1951 la población incrementó 10 veces en tamaño. De 1951 a 1985, la población se quintuplicó y para los últimos 34 años se duplicó. Ahora, si analizamos la tasa migratoria y su contribución a la tasa total encontramos lo siguiente.

Entre 1905 y 1951 la población migratoria se incrementó aproximadamente en un $53 \%$ (ver tabla 3 ). Así mismo entre 1951 y 1985 esta misma tasa fue de un $51 \%$; para los últimos treinta años tiende al 31\%. Durante el último siglo la tasa migratoria en promedio giro alrededor de
$44 \%$, es decir que de cada 10 habitantes casi la mitad de ellos es de otros municipios. Cabe anotar nuevamente que la mayoría de los migrantes desplazados por la violencia que llegan a los centros urbanos reclaman atención a sus demandas.

Tabla 3. Comportamiento demográfico Cali (1905-2015)

\begin{tabular}{|c|c|c|}
\hline Año & Tasa vegetativa & Tasa migratoria \\
\hline 1905 & 58 & 42,0 \\
\hline 1912 & 58,1 & 41,9 \\
\hline 1918 & 28,3 & 71,7 \\
\hline 1928 & 53,4 & 46,6 \\
\hline 1938 & 49,2 & 50,8 \\
\hline 1951 & 37,5 & 62,5 \\
\hline 1964 & 47,8 & 52,2 \\
\hline 1973 & 57,7 & 42,3 \\
\hline 1985 & 52,6 & 47,4 \\
\hline 1993 & 45,3 & 54,7 \\
\hline 2005 & 99,1 & 0,9 \\
\hline 2010 & 65,9 & 34,1 \\
\hline 2015 & 80,7 & 19,3 \\
\hline
\end{tabular}

Fuente: Urrea (2011).

\section{La planeación urbana y su relación con el desarrollo territorial}

La planeación se conoce como el conjunto de procesos que tienden al ordenamiento de recursos en el futuro posible y deseable. Por ello, los planes, programas y proyectos 
2 Entiéndase por politicas macro politicas sociales $y$ estructurales a largo plazo conducentes a desarrollo en infraestructura como servicios públicos, salud, educación, desarrollo territorial, etc.

\section{territarias 42}

de desarrollo introducen la evaluación de las actividades en la cual el ordenamiento se sustenta (Vallderuten, 1999). En relación a la planeación y al desarrollo urbanoregional, el interés por la planificación a nivel mundial se contextualizó a través de políticas macro ${ }^{2}$ adoptadas durante el Estado interventor de corte Keynesiano (1930-1980).

En Colombia entre 1950 y 1980, la planificación se justificó desde la visión del Estado desarrollista, promotor de la prestación de servicios sociales y de la construcción de obras públicas en la parte rural y urbana (Varela, 2001). Es decir, durante el periodo de la Guerra Fría, el Estado interventor se posicionó como garante y subsudiador de las necesidades básicas de la población, bajo un lenguaje proteccionista. Durante este periodo de bienestar, el Estado jugó un papel primordial en la prestación de servicios como construcción de hospitales, carreteras, vías férreas, puertos, centrales eléctricas, educación, salud, vivienda, y otras obras públicas, tanto en la parte rural como en la urbana.

Por otra parte, la planeación de influjo modernista fue impulsada también a nivel mundial por el CIAM (Congrès International d'Architecture Moderne), sus lineamientos están aún presentes en las urbes latinoamericanas con el argumento de la tecnosociedad, es decir se buscó resolver las crisis urbanas en los contextos del capitalismo mediante intervenciones estadocéntricas direccionadas a la rein- vención social. Se trató de una experimentación con tecnologías científicas/ espaciales/sociales. En Latinoamérica durante la década de los cincuenta del siglo xx el influjo modernista impulsó obras de renovación urbana como los mercados populares y chicherías. Estas dinámicas modernistas fueron la base de la desfamiliarización, la descontextualización y el determinismo ambiental, tal como lo indicó James Holston en 1989 en un estudio sobre Brasilia. La aplicación de este inhumano concepto en América Latina explica la historia de la segregación y la exclusión en los territorios (Pérez, 2010).

En el caso de la ciudad de Cali, en relación con la planeación, se encuentra que para 1944 "la elite político-empresarial de la ciudad" contacta al urbanista Karl Brunner, quien elabora un diseño denominado Plan Cali Futuro de acuerdo a un desarrollo lineal entre los municipios de Yumbo y Jamundí (Arboleda \& Rivas, 1991; Chaparro, 1998; Vásquez, 2001). Igualmente, durante la década de los cincuenta el proyecto de Wiesner y Sert (DAPM, 1979) determinó la planeación física y el mapa oficial de vías, mediante la primera norma de planeación nacional Ley 88 de 1947. A raíz de esto, en 1953 surge la Oficina del Plan Regulador (el origen de planeación municipal) y el diseño del Plan Piloto, que explica el desarrollo espontáneo, acelerado de la ciudad y ampliado en sus alcances de superficie.

Hay que plantear y reconocer que el desarrollo urbano ha estado influenciado 
por las lógicas del poder, entendido como las dinámicas tradicionales, políticas y económicas en las que interactúan ciertos actores que tienen una característica innata y natural, además son una minoría ordenada que debe orientar a una mayoría desordenada, a juicio de Wilfredo Pareto esta definición tiende a la noción de elite. ${ }^{3}$

Desde tiempos coloniales, los ideales modernistas se han guiado por la noción de orden como producto de civilización; en función de este contexto las elites en Bogotá, Medellín y Cali lo han clasificado respecto a tipologías como categorías sociales y raciales en un esquema de control societal que se establece con lo urbano (Pérez, 2010). En el caso de Barranquilla entre 1878 y 1906 la elite local desarrolló el tejido urbano en usos comerciales, que con el paso del tiempo los destinaron a la industria (Solano \& Conde, 1993). En un hecho análogo, el caso mexicano revela cómo las elites político-económicas impulsaron las ideas de modernidad en la transformación de la capital mexicana exacerbando también la segregación urbana y la polarización social: la planeación urbana fue utilizada como un instrumento de poder y dominación (Valenzuela, 2012).

Con todo, la noción de modernidad es un concepto tardío en Latinoamérica, que se tradujo en la construcción del Estado-Nación, la industrialización y la migración del campo a la cuidad de acuerdo a un concepto de racionalidad tecnomoral administrado por las elites.
Es por ello, que las elites colombianas dentro de su control social modernista del territorio planificaron y urbanizaron las ciudades para las clases pudientes. De igual forma, sometieron a los sectores pobres expulsándolos a la periferia de los municipios - tal cual como sucedió en la Edad Antigua con los sirvientes y los esclavos en la polis griega-.

\section{El desarrollo histórico urbano- territorial de la ciudad de Cali}

Desde el análisis descriptivo, el desarrollo de la ciudad de Cali muestra una tendencia que va muy ligada a su crecimiento tanto poblacional como territorial, cuyo punto de partida se hace más pronunciado iniciando el siglo Xx (ver figura 2).

Desde el contexto histórico se tiene que durante los siglos XVI al XIX, Cali fue un referente pequeño de no mucha relevancia en el contexto regional porque las provincias de Buga y Popayán tenían mayor poder político y económico. Desde estas eras, Cali significó un camino obligado de paso para quienes viajaban al sur a Ecuador o Perú. Hay que recordar también que su única posibilidad de conexión al océano Pacífico se había realizado por el precario y difícil camino entre CaliBuenaventura. En estos tiempos, durante los siglos previos al Xx, el contexto parroquial caleño fue escenario de cohabitación de hacendados, terratenientes, mineros, comerciantes, artesanos, jornaleros, indígenas, manumisos, mulatos y población
${ }^{3}$ La elite está compuesta por quienes tienen unas cualidades excepcionales en relación a su autoridad, poder y dominación en toda sociedad. Hay quienes gobiernan, administran y dirigen (minoria) y otros que obedecen (el conjunto de la población). Para el caso de la ciudad de Cali, desde el siglo XIX y XX, la elite es una clase social de dueños de haciendas y empresas, los cuales detentan el poder político como mecanismo de acción personal con una racionalidad máseconómica-utilitarista que social. En últimas a esta clase politica le interesa más el dinero, el prestigio y el poder que implica gobernar.

tersitarios 42

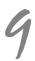


Figura 2. Crecimiento poblacional de Cali (1580-2015)

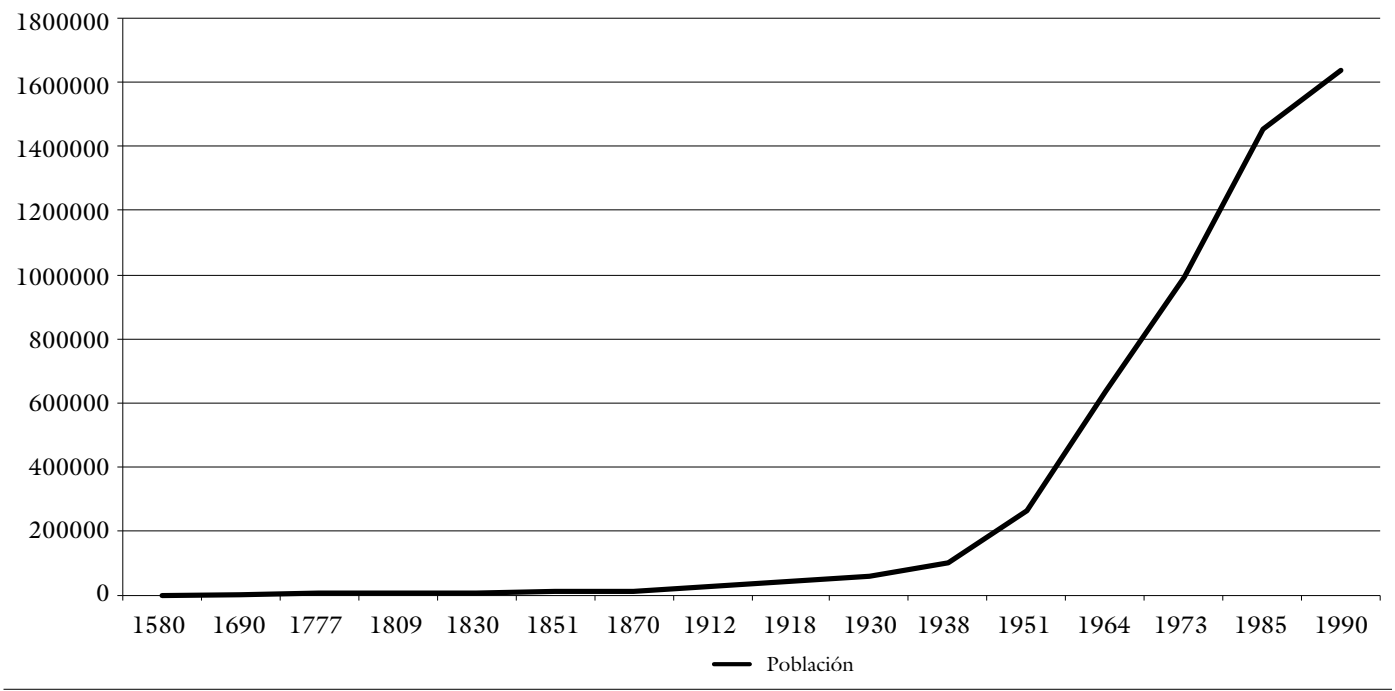

Fuente: elaboración propia.

negra de servidumbre (aun así, la población nunca superó los 15000 habitantes). Desde las actividades económicas, Cali se mantuvo del sector agropecuario de las haciendas y cultivos de pancojer, que tenía como escenario un mercado local limitado. En relación a su infraestructura vial sus caminos eran de herradura los cuales iniciaban desde la plaza mayor o plaza de la constitución (hoy Plaza de Caicedo) con carruajes, mulas y caballos (Vásquez, 2001; Vergara, 2005; Pérez, 2007).

Asimismo, el desarrollo urbano-regional de Cali fue liderado por una elite de empresarios que tuvo sus inicios con la economía precapitalista agraria de la hacienda. En este contexto surge una clase política que proviene de negociantes, banqueros y empresarios, los cuales encontraron la posibilidad de un mercado en el eje comercial Cali-BuenaventuraPanamá. Desde la conformación de un mercado local y empresarial, la urbe caleña se convirtió en el epicentro del desarrollo regional en las primeras dos décadas del siglo Xx. Bajo este influjo económicoempresarial se ganó el espacio político que determinó a Cali como la capital del nuevo departamento del Valle en 1910 (Arroyo, 2006).

Al respecto, a partir de la creación en 1910 del Departamento del Valle del Cauca como ente territorial, la ciudad de Cali se erigió como una urbe en el contexto regional y comercial, dado el posicionamiento del café colombiano en el comercio internacional la ciudad se iniciaba como epicentro de negocios y empresas por su 
cercanía con el puerto de Buenaventura, además, instituciones como el ferrocarril y el transporte terrestre así la consolidaron. Por lo tanto, la modernidad empezó a hacerse evidente en la infraestructura de la urbe en hechos como los primeros edificios en altura, la industrialización y el barrio obrero, la primera planta eléctrica y el tranvía (1910), el primer automóvil en 1913, el ferrocarril desde 1915, el transporte a vapor en 1925 , las empresas de servicios públicos municipales en 1930 y la Escuela Militar de Aviación (1933). Estos aspectos fueron reflejos de un territorio que se alejaba de su versión decimonónicacolonial con miras de catapultarse hacia un proyecto Estado-nacional progresista clasista de urgente modernidad (Alcaldía de de Cali-DAPM, 1990; Londoño, 2011; Ramírez, 2011).

Empero, la ciudad de inicios del siglo XX continuaba aún con el mantenimiento de una herencia institucional colonial (path dependance) por intermedio de las elites hegemónicas de origen familiarempresarial con serios intereses marcados en lo político y en lo económico en un factor de dominancia hacia las capas más bajas de la sociedad con una tipología societal al mejor estilo de la ley de hierro oligárquica-burocrática (Michels, 2001) donde estas organizaciones familiares han regido y rigen el orden regional-urbano hasta el presente.

Entre 1910 y 1940 la ciudad de Cali empieza a tener una serie de infraestructuras en función a su desarrollo y en relación con la conectividad en el territorio, aspectos como el surgimiento de la industria, la generación de energía eléctrica, el ferrocarril, una red multimodal y de transporte, una sociedad de mejoras públicas, dos notarías, una escuela de aviación, cinco periódicos, un taller de ferrocarril en Chipichape, cuatro clubes sociales, un aeródromo, 10 bancos, 20 ingenios azucareros, 10 empresas multinacionales y una estructura de servicios públicos son elementos propios del proceso de modernización encausado por esta clase dirigente (Arroyo, 2006, pp. 34-36).

Durante este tiempo la dirigencia local, hegemónica y empresarial es posicionada en los principales órganos de la administración pública y sus negocios privados trajeron el tranvía, las bicicletas, los automóviles; además construyeron calles, carreras, avenidas, puentes e introdujeron una serie de bienes consumidos fundamentalmente por ellos. Es decir, el desarrollo de la ciudad estaba siendo precedido por el comportamiento patrimonialista y patriarcal de su clase dirigente. A la par de este desarrollo surgen también los movimientos sindicales que chocaban contra estas elites en el poder y que no tienen cabida en los partidos políticos tradicionales (Aprile-Gniset, 1992, p. 15).

No hay que dejar de lado que entre los negocios de esta elite en el poder está el diseño del modelo de ciudad en relación a su racionalidad económico-empresarial, es decir, el desarrollo urbano de $\mathrm{Cali}^{4}$ se encauzó políticamente vía el Concejo
4 Ver: http://historico. elpais.com.co/paisonline/calionline/notas/ Julio262009/empedrado. btml

territarias 42 
5 Para Aristóteles, el cuestionamiento central sobre el ciudadano se refiere a quien tiene derecho $y$ libertad de participar del gobierno, del consejo y de la judicatura.

\section{territarias 42}

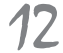

Municipal sobre las propiedades de sus antiguas haciendas, fincas, ingenios y lotes de pastoreo, inclusive sin el menoscabo de modificar sus nombres los cuales obedecen hoy a barrios como la Floresta, Salomia, el Cascajero (obrero), el Peñón, Santa Rita, Versalles, Santa Mónica, Chipichape, Menga, San Luis, La Selva, Aguablanca, El Rodeo, El Guabito (Base Aérea), El Guabal, El Limonar, Pasoancho, Cañaveralejo, Los Chorros, San Antonio, Isabel Pérez (San Fernando), Santa Isabel, Meléndez, San Joaquín, etc. (Escorcia, 1981; Vásquez, 2001).

Llama la atención que el territorio urbanizable se destinó a la clase pudiente de la sociedad, es decir, a la que denominan ciudadano (al mejor estilo de la Grecia antigua), por lo tanto, cabe recordar en una cuestión de semejanza histórica que el ciudadano griego es un sujeto políticoracional que actúa, delibera y participa en el ágora (Vernant, 2001). Desde lo político el sujeto de la polis vive en un mundo de iguales siempre y cuando se le considere al otro como ciudadano (sustancia común $)^{5}$ $\mathrm{y}$, sociológicamente hablando los siervos y los esclavos están en las capas más bajas de esta sociedad por ello están por fuera de la ciudad.

De igual manera, Aristóteles resalta en el libro Politica cómo repartir las magistraturas entre los ciudadanos, la cual se debe repartir de acuerdo con sus semejanzas para que no haya diferencias con respecto a la concepción de justicia, por lo que su igualdad hará referencia a aquellas cosas que constituyen la ciudad. Lo que significa que la urbe o la polis integra a sus ciudadanos en un mismo plano salvo a los esclavos que están por fuera de la humanidad.

Volviendo al contexto histórico de Cali, su clase dirigente elitista comercializó ejidos y lotes en la periferia de la ciudad ubicados al oriente, nororiente y suroriente, es decir, los terrenos menos fértiles, inundables y alejados de la urbanización, los cuales fueron asumidos por sectores populares que incluían entre otros a población de escasos ingresos como también a desplazados por la violencia del conflicto interno. Esta clase desposeída y excluida formó parte del anillo periférico del desarrollo subnormal que correspondía a los cerros bajos de la ciudad en el noroccidente y occidente, como también a la planicie oriental adyacente a los ríos Cali y Cauca (Hurtado, 2010). Esta clase a la que se consideró marginal fue el apalancamiento político de la clase dirigente en el poder debido a que las elites lograron captar y capitalizar las demandas y necesidades de los sectores populares frente a la creación y legalización de los barrios periféricos. En ultimas, la implementación de políticas públicas territoriales definió la estructura urbana en relación a la conformación de una estructura de clases sociales (Sáenz, 2010).

De otra parte, entre las décadas de los años veinte y sesenta del siglo XX, la ciudad y el país transitaban alrededor de la conformación de un contexto empresarial 
e industrial que buscaba fortalecerse con firmas locales y extranjeras en un modelo de sustitución de importaciones en torno a bienes de consumo, bienes intermedios y de capital en rangos como los ingenios azucareros, las industrias de alimentos, las imprentas, las industrias de polímeros, de caucho y papel y la industria de gaseosas, fortaleciendo también las empresas de seguros, la banca y las finanzas, el comercio exterior, el sector agropecuario, etc. (Kalmanovitz, 2015). Todo este contexto se desarrolló desmitificando la leyenda de la pujanza paisa para dar lugar al origen y la lucha del espíritu empresarial-organizacional vallecaucano como también la de empresarios pioneros raizales (Ordoñez, 1995).

Frente a esto se puede analizar entonces que la industrialización es evidente en el desarrollo urbano. Falta incluir en estas categorías la migración poblacional hacia Cali, que en estas épocas es generada por motivos de empleo, seguridad y bienestar, lo cual impactó en la expansión de la urbe (Vergara, 2005). A la zaga de este desarrollo industrial-territorial se inician también los procesos de planificación urbano-regional en la década de los años cuarenta y setenta a través de los enclaves regionales-empresariales lo que concentraría aún más escenarios como la conurbación bajo los esquemas de las áreas metropolitanas, hecho que se considera como una verdadera revolución urbana (Martínez, 2016).

\section{Hacia el desarrollo metropolitano de Cali}

El término primacía urbana hace referencia a hechos que describen la evolución o el crecimiento de las ciudades en aspectos como el éxodo rural (la migración campociudad), la demografía, la industrialización y la relevancia en infraestructuras de una ciudad frente a su red de municipios en una región o país, que en conjunto llevan a una acentuada concentración urbana (Cuervo, 2004; Montoya, 2013).

Por ello, desde la década de los años cincuenta Cali alberga talleres, fábricas e industrias en la zona comprendida entre las carreras 1 y la 15 y entre las calles 13 y 70 hacia el nororiente. Además, la capacidad instalada de la industria pesada se había concentrado sobre la autopista Cali-Yumbo. En este aspecto, la capital del Valle ha liderado el nodo industrial de la región. Cabe recordar que en términos poblacionales Cali es el epicentro de esta zona (tabla 4). Por lo tanto, desde inicios de siglo XX siempre ha tenido la primacía urbana del suroccidente colombiano (Vergara, 2012).

Esto significa que la primacía de Cali sobre las ciudades más importantes de la región ha estado siempre presente en esa centuria: por ejemplo, en términos proporcionales ha tenido cinco veces mayor población que las ciudades del triángulo del café (Manizales, Pereira y Armenia) incluyendo a Ibagué. Además, su evolución histórica también lo ratifica como se 
Tabla 4. Jerarquías poblacionales del suroccidente

Colombiano (1973-2005)

\begin{tabular}{|l|c|c|c|c|}
\hline \multicolumn{1}{|c|}{ Ciudad } & Población 1973 & pobCali/pob & Pob 2005 & pob Cali/pob \\
\hline Cali & 971891 & 1.0 & 2039626 & 1.0 \\
\hline Ibagué & 202850 & 4.8 & 465859 & 4.4 \\
\hline Pereira & 186776 & 5.2 & 358681 & 5.7 \\
\hline Manizales & 202607 & 4.8 & 342260 & 6.0 \\
\hline Pasto & 130202 & 7.5 & 312759 & 6.5 \\
\hline Neiva & 109063 & 8.9 & 295412 & 6.9 \\
\hline Buenaventura & 110713 & 8.8 & 290457 & 7.0 \\
\hline
\end{tabular}

Fuente: elaboración a partir de DANE (2015).

percibe en los censos desde 1973 hasta 2005. De igual manera, ocurre con las ciudades de Pasto, Neiva y Buenaventura, cuyas cifras indican que estos municipios tienen seis veces menos población que Cali; es decir, la importancia de la urbe caleña como nodo regional siempre se ha mantenido (figura 3).

De otra parte, en plena década de los años sesenta el Plan Piloto o Plan Regulador de 1950 aún regía la planeación física de Cali, el cual correspondía a la movilidad lineal norte-sur entre Yumbo y Jamundí. La normatividad vial buscaba la conexión con el sur de la ciudad, prueba de ello es la Avenida Roosevelt hasta el templete, el trazado de Menga a Meléndez por medio de la Autopista sur, la construcción de la calle 10, la avenida circunvalar hacia el sur, la avenida Pasoancho y la Autopista Simón Bolívar. Así como la pavimentación

Figura 3. Jerarquías poblacionales del Suroccidente colombiano (1973-2005)

\section{territarias 42}

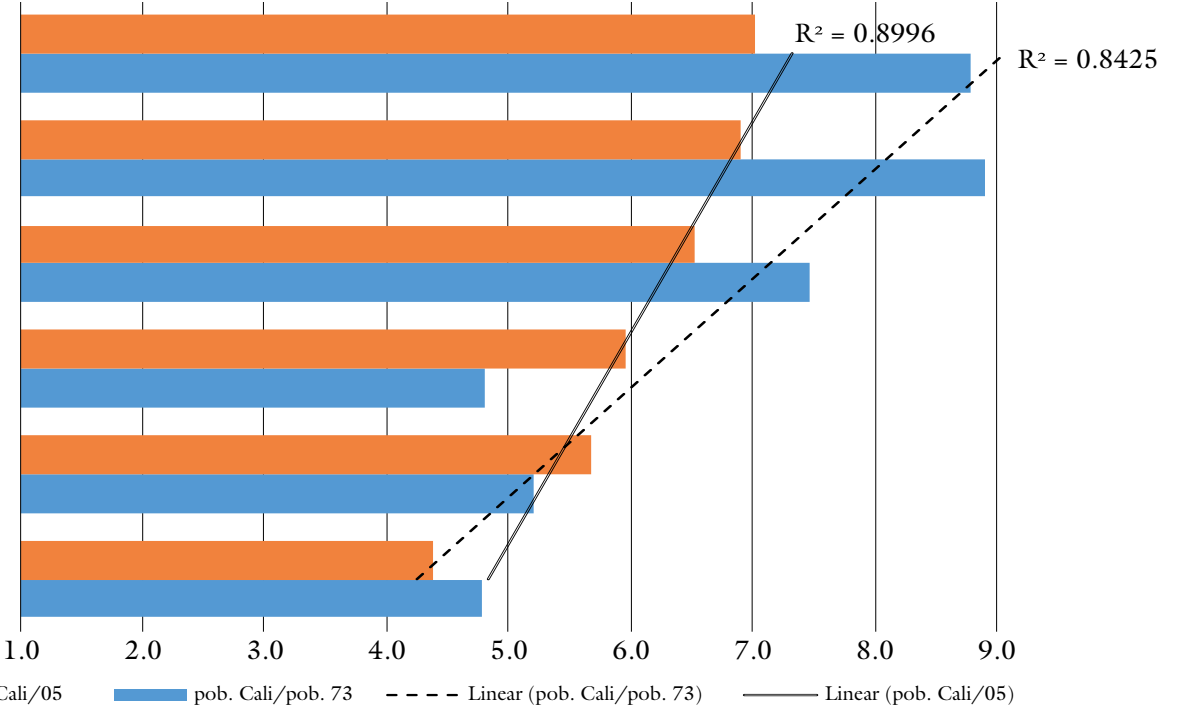

Fuente: elaboración a partir de DANE (2015).

Rafael Vergara Varela, Jorge Enrique Arias Calderón, María Eugenia Rodríguez Vásquez 
de las calles 34 y 44 desde el norte hacia el oriente (Vásquez, 2001; Vergara, 2005). En 1964 se realiza el proyecto de nomenclatura de vías y predios.

Sin embargo, en 1967 el hito más importante de la transformación urbana responderá a la designación a los VI Juegos Panamericanos de 1971. En respuesta a la proximidad del evento deportivo se realizaron los estudios que complementaron el Plan General de Desarrollo de 1969: el Plan de Inversiones 1968-1971, el estudio de los usos del suelo y el estudio de los anillos. Hay que destacar que las obras viales aceleraron la transformación urbana, pero se debe señalar que el proceso ya estaba en curso y el cambio urbano respondió tanto a la política de expansión residencial, como a la solución para mejorar la circulación del creciente parque automotor en una ciudad con atraso vial.

Asimismo, cabe recordar que en 1967, el 77\% de las vías de Cali estaba sin pavimentar; por ello el resultado de la ejecución del plan vial significó la reducción del déficit en más del $60 \%$ para 1971 . Por lo tanto, no se debe desconocer que la coyuntura de los Juegos Panamericanos permitió la modernización urbana, además de la ampliación de la ciudad en todas las direcciones, pero sobre todo al sur, sumado al desarrollo de infraestructuras institucionales importantes como la semaforización en la ciudad, los parqueaderos a niveles o por pisos, el Plan Muelas (la demolición de viejas casonas para ampliar las vías céntricas), la continuación de la carrera $\mathrm{l}^{\mathrm{a}}$ entre la calle 15 y la autopista oriental, la consecución de la calle 15 entre carreras $1^{\mathrm{a}}$ y 15 , la construcción de la Avenida Guadalupe, la prolongación de la carrera 15 entre la calle 25 y la autopista sur, la repavimentación de la calle 25 a la altura de la estación del ferrocarril hasta la carrera 15 , el mejoramiento y ampliación de la calle $5^{\text {a }}$ desde la carrera $1^{\text {a }}$ hasta el Hospital Departamental, la Avenida Joaquín Borrero frente a las piscinas panamericanas, el Coliseo y el velódromo, la Unidad Deportiva Panamericana, la construcción del Aeropuerto de Palmaseca, la construcción del Hotel Inter-Continental, la Central Interurbana de Transporte y la ciudad universitaria de Univalle en Meléndez (Planeación Municipal, 1990; Vásquez, 2001; Vergara, 2005; Camacho, 2006b).

Esta etapa histórica e importante del desarrollo urbano de la década de los setenta está siendo considerada a juicio de algunos escritores, académicos e investigadores como una "segunda modernidad", pero realmente debería ser una "segunda revolución urbana" que es coyuntural y estructural con la política nacional denominada Las Cuatro Estrategias y su lineamiento La construcción como sector lider, elaborada por el profesor Lauchin Currie ${ }^{6}$ e implementada en la administración de Pastrana Borrero, que se orientó al desarrollo urbano a través de la generación de vivienda tanto por el sector público como el privado, a través del Instituto de Crédito Territorial (ICT en adelante) y las Corporaciones de Ahorro y Vivienda
- El profesor Lauchin Currie viene argumentando sobre la idea de "la ciudad dentro de la ciudad" como politica del desarrollo urbano, dado que la construcción se convirtió en el motor del desarrollo de la economía colombiana. 
mediante la creación del UPAC hoy UVR (Departamento Nacional de Planeación, 1972; López, 2011).

Lo que se va a presenciar en las décadas posteriores a la del setenta en Colombia es una explosión urbana producto de la política Las Cuatro Estrategias y del crecimiento del sector de la construcción en la realización de vivienda, así como de la ejecución de obras públicas especialmente en la expansión y cobertura de los servicios públicos domiciliarios (Fainboim \& Rodríguez, 2000; Camacol, 2008).

Para el caso de la ciudad de Cali, entre las décadas de los setenta, ochenta y noventa, las obras residenciales se localizaron en la zona de expansión en el sur de la ciudad. Durante este tiempo en el sector norte hubo limitaciones de tipo ambiental ocasionadas por la contaminación proveniente de la zona industrial Cali-Yumbo. Empero, se construyeron nuevos barrios por parte del ITC en los ochenta como Chiminangos, Alcázares y Floralia en el nororiente, y soluciones de vivienda por parte de Invicali en la planicie oriental como fue el caso de Petecuy (Velásquez \& Jiménez, 2004).

También en estas décadas, inicia el poblamiento informal y acelerado en el oriente en el Distrito de Aguablanca del cual surgen barrios como El Vergel, Charco Azul, Mojica, El Vallado, Comuneros, Marroquín, los Naranjos, el Poblado, Manuela Beltrán, Puertas del Sol, Alirio Mora, Decepaz, etc. (Mosquera, 1989; 1996). Efectivamente, como se puede ver en la figura 4 , hacia finales

Figura 4. Comportamiento porcentual de la cobertura de los servicios públicos en Cali (1979-2003)

\section{territarias 42}

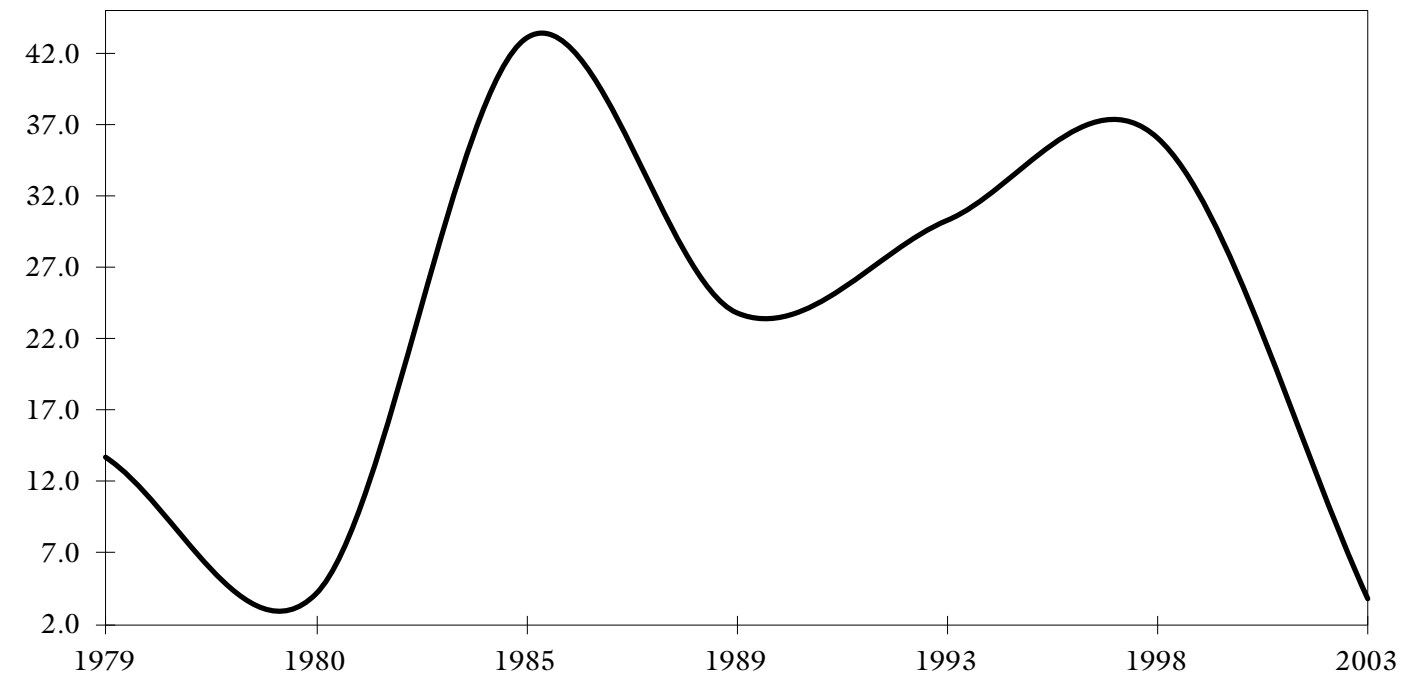

Fuente: elaboración propia. 
de 1979 hubo un crecimiento importante en la cobertura de servicios públicos con tasas superiores al 35\%, el cual se explica principalmente por la expansión desbordada hacia el distrito de Aguablanca, que implicó por ende la urbanización y dotación de esta zona de inversiones en los servicios básicos por más de veinte años.

Esta invasión en desbandada en una zona subnormal le significó a la Empresa de Servicios Municipales de Cali (Emcali) altos costos de operación y de sus finanzas, pero especialmente el mayor impacto negativo lo sufrirá la ciudad con altos costos sociales, además de altas inversiones en infraestructura de bienes públicos como también elevados costos de urbanización, los cuales hoy en día aún no se resuelven (Aprile-Gniset, 1992; Camacho, 2006a).

\section{El modelo de ciudad y su congestión urbana}

Durante la década de los noventa las obras realizadas en términos de infraestructura urbana y vial fueron la prolongación de la Avenida Pasoancho hasta la calle 100, la prolongación de la calle $9^{\mathrm{a}}$ hasta la carrera 66 , la prolongación de la calle 12 hasta la carrera 63 , la prolongación de la carrera 44 , los puentes de las carreras 44 y 50, la ampliación de la calle $7^{\mathrm{a}}$. Al hacer un balance de la periodización trabajada hasta aquí se encuentra que ante este crecimiento territorial entre los años 1940 y 1990 se incorporaron al casco urbano de Cali 30523 hectáreas (tabla 5).

Tabla 5. Población, superficie, vías y vehículos en Cali (1910-1990)

\begin{tabular}{|c|c|c|c|c|}
\hline Años & Población & Superficie (ha) & Vías $(\mathrm{km})$ & Vehículos \\
\hline 1910-1929 & 60000 & 300 & 64 & 239 \\
\hline 1930-1949 & 241300 & 1290 & 260 & 5000 \\
\hline 1950-1959 & 618200 & 3493 & 700 & 20000 \\
\hline 1960-1969 & 991549 & 6353 & 950 & 60000 \\
\hline 1970-1979 & 1241585 & 8027 & 1362 & 106000 \\
\hline 1980-1990 & 1637527 & 11166 & 2350 & 154123 \\
\hline
\end{tabular}

Fuente: elaboración propia.

Llama la atención de las cifras de la tabla 5, que entre 1910 y 1959 en un periodo de casi 50 años, la población, la superficie, las vías y los vehículos tienden a incrementarse de manera proporcional en cerca de 10 veces más su valor inicial, pero desde 1960 la proporcionalidad se pierde debido al aumento poblacional dado que como se había explicado anteriormente, la ciudad de Cali es un centro regional por el cual se explica su incremento poblacional. Como un aspecto importante se encuentra también que la urbe responde a la contextualización de las ciudades en expansión donde de igual manera se va incrementando su parque automotor a medida que pasa el tiempo (figura 5 ).

Como se puede apreciar en la figura 5 , a partir del año 1950 hay un incremento considerable del parque automotor que se explica porque por cada 31 habitantes hay un vehículo; treinta años después se reduce a 11 habitantes. Como la curva es decreciente es de esperarse entonces que en el nuevo milenio esta cifra se haya territarios 42

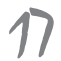


Figura 5. Vehículos per cápita en Cali (1910-1990)

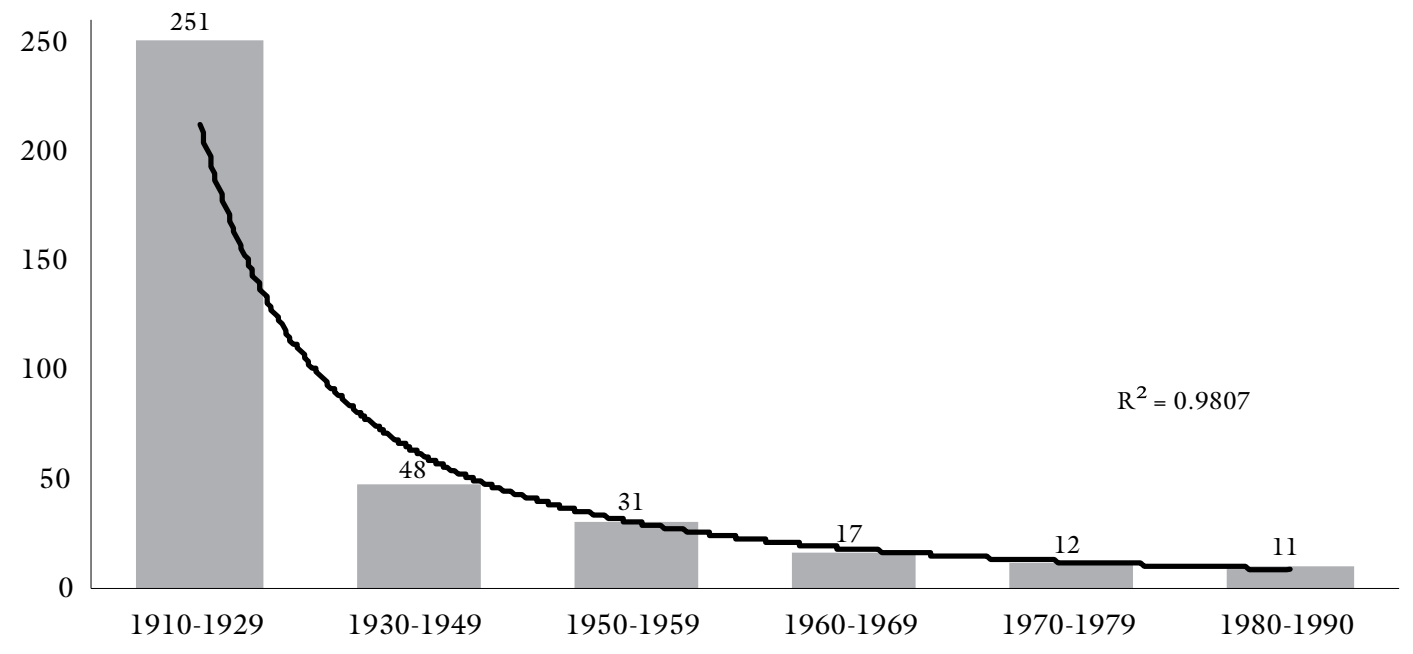

Fuente: elaboración propia.

reducido aún más, entre otros por la facilidad de compra de vehículos, lo cual es coherente dado el problema actual de movilidad y congestión vehicular con el que convive la ciudad.

Por otra parte, como consecuencia del crecimiento urbano de los últimos veinte años en Colombia, para 1999 se aprueba una ley que busca regular la planificación del territorio, conocida como Ley 388 o Ley Orgánica del Ordenamiento Territorial, un instrumento jurídico para armonizar holísticamente el ordenamiento territorial y ambiental de los municipios en nuestro país (Prieto \& Luengas, 2011). En concreto, la Ley 388 buscó generar una descentralización a través de un instrumento de planificación en los municipios por intermedio de los planes de

\section{territarias 42} 18 vez buscan conjugar en medio de la complejidad urbana las políticas territoriales de orden económico, ambiental y administrativo con énfasis en áreas de expansión y metropolitanas, espacio público, usos del suelo, centralidades, servicios públicos, movilidad, medio ambiente y gestión del suelo dentro de los mismos municipios, obviamente armonizando el desarrollo desde la visión integral e innovadora de territorios ecosostenibles (Massiris, 2002).

El pensar la urbe siempre trae consigo la reorganización físico-urbana, normalmente esta se encuentra ligada de manera histórica a espacios y edificios, cuyos usos son emblemáticos, de carácter institucional, que se encuentran referenciados en otros intereses y valores sociales dados los procesos de modernización de la ciudad de acuerdo al desarrollo de necesidades 
de diversa índole (económicas, políticas, sociales o culturales) de los habitantes y de su posibilidad de desplazamiento a través de ella (Palacios \& Moreno, 2012, p. 11; Mayorga, 2013).

De esta forma, la relación de infraestructura urbana se consolida a través de la historia de la ciudad y su proceso de construcción (Mayorga, 2013, p. 14). Por ello, es oportuno vislumbrar herramientas de gestión pública como los POT del 2000 y del 2014 para tener presente el proceso anterior a la formulación e implementación de estas, ya que configuran de manera discursiva la transformación de la urbe a partir de sus relaciones sociales, económicas, políticas y culturales (Jiménez, 2005, p. 29). En el caso de Cali eso significó el paso de un "urbanismo feudal" a una evolución en la planificación donde se entremezclaron el crecimiento compacto, con base en la demanda habitacional, con una expansión discontinua, dispersa y descontrolada (Mosquera, 2011, p. 8).

Ahora bien, en el nuevo milenio, especialmente con relación al ordenamiento de la ciudad de Cali, y haciendo un balance de este proceso urbano, se encuentra que los POT de los años 2000 y 2014 han presentado más descripciones de problemas públicos que logros efectivos frente a ellos, los cuales desdibujan la intencionalidad de un verdadero modelo de ciudad. Es decir, este modelo o paradigma urbano no está claramente definido porque los planes anteriores a la presente centuria como el Plan Piloto de 1950, el PGD de
1969 y el Pideca de 1980 fueron más de orden expansivo, rentístico y patrimonial que verdaderos proyectos integrales de ciudad. ${ }^{7}$ Sumado a lo anterior, los planes en mención no se ven reflejados transversalmente en los programas de gobierno municipal de los últimos 17 años. En consecuencia, hay temas básicos del POT que hacen ingobernable la ciudad como por ejemplo el problema de la escasez de agua en Cali. A la fecha no hay un plan maestro implementado que sirva para recuperar las siete fuentes hídricas o cuencas hidrográficas que sirven a la ciudad. La evidencia ha mostrado que esto es un tema pendiente y sin resolución de parte de la administración municipal.

En estos elementos de estudio basta recordar que sobre los planes maestros históricos (1950, 1969 y 1980) se montaron los POT del nuevo milenio para Cali. Un ejemplo del desacierto analítico sobre la ciudad es la mala concepción e identificación en el tema de la desconcentración de actividades en el centro histórico-institucional, conocido como descentralización urbana la cual se venía definiendo desde el PGD de 1969, y 40 años después se articula a los planes actuales desconociendo el sentido propio y real de una centralidad en medio de la dinámica espacial urbana (Vergara, 2009).

De igual manera ocurre con el supuesto implícito y fundamental de estos planes como es la sostenibilidad, cuyo concepto debería ir más allá de la "sostenibilidad clorofila", es decir analizar la sostenibilidad es
7 Prueba de ello es el poblamiento y expansión del distrito de Aguablanca. 
un tema holístico en términos económicos, políticos, sociales y culturales. Es por ello que estas malas definiciones y comprensiones conceptuales sobre lo territorial hacen que los planes lo sean también (Martínez, 2016). Así se encuentra también el artificio de las áreas metropolitanas definidas en las normas territoriales hace 50 años, pero que en la práctica en la ciudad de Cali no existen, y mucho menos se ponen de acuerdo los municipios circunvecinos para tal fin. Es de tal tamaño el problema que incluso cuando se habla de la ciudadregión (G-11) todavía no hay ninguna concreción efectiva.

Tabla 6. Participación porcentual de los usos del suelo, Cali 1969-2021

\begin{tabular}{|l|c|c|c|}
\hline \multicolumn{1}{|c|}{ Usos } & $\mathbf{1 9 6 9}$ & $\mathbf{1 9 9 0}$ & $\begin{array}{c}\text { 2021 según } \\
\text { tendencia }\end{array}$ \\
\hline Residencial & 39,1 & 46,0 & 54,3 \\
\hline Industrial & 3,5 & 2,7 & 1,7 \\
\hline Comercio/Servicios & 4,1 & 4,4 & 4,6 \\
\hline Vías & 37,1 & 29,4 & 19,4 \\
\hline Zonas Verdes & 7,6 & 6,0 & 4,0 \\
\hline $\begin{array}{l}\text { Equipamiento } \\
\text { Institucional }\end{array}$ & 8,6 & 11,4 & 16,0 \\
\hline
\end{tabular}

Fuente: Planeación Municipal Cali - РОт 2000 y 2014.

Asimismo, aún persisten en los POT (2000 y 2014) vacíos en la forma de pensar el territorio, por ejemplo desde hace 50 años Planeación Municipal viene hablando sobre el transporte colectivo para mejorar la movilidad y la integralidad del municipio a través de diferentes alternativas como el tranvía, el metro, el tren de cercanías, el transporte ligero, el transporte masivo, etc. Sin embargo, en 2019 ni la conectividad interna ni externa de la urbe se ha solucionado, mucho menos la administración municipal con sus secretarias (planeación y tránsito-movilidad) encuentran medidas para resolver el grave problema de la creciente congestión vehicular.

Según la información de los planes territoriales de 2000 y 2014 , se encuentra en primer lugar que hay una clara tendencia de crecimiento al año 2021 de usos residenciales, comercio y equipamiento institucional, es decir, hay una expansión en áreas que es probable que sea en altura, dada la escasez de terrenos en Cali. En segundo lugar, desde esta misma compresión se encuentra que los usos del suelo para la industria, en vías y en zonas verdes han venido decreciendo paulatinamente en los últimos 48 años (tabla 6). Es de advertir que ese decrecimiento es más pronunciado en los usos del suelo destinados para las vías con decrecimientos constantes a tasas del 10\% cada veinte años desde 1969.

En los POT 2000 y 2014 de Cali, la movilidad está siendo abordada como un sistema, basta recordar que la integralidad de este sistema no existe. En este modelo coexisten a su vez cinco subsistemas: transporte en bicicleta, peatonal, transporte colectivo o masivo, transporte privado y transporte de carga o logístico. Respecto al subsistema de transporte privado el diagnóstico reconoce el problema del tráfico 
vehicular y la congestión, pero no aparecen soluciones integrales. Tampoco hay recomendaciones de política para intervenirlo. Además, los proyectos en infraestructura vial son una agenda pendiente.

En Arboleda et al. (2012) se estudia el impacto negativo que se genera en Cali debido a la congestión en las vías. Como se puede ver en la tabla 7 y en la figura 6 , desde el año 2015 el número de vehículos por kilómetro supera la cifra de 200 automotores y se espera que al año 2020 sean 282 autos en un kilómetro vial.

Tabla 7. Densidad vehicular años 2010-2020

\begin{tabular}{|c|c|c|c|}
\hline Año & Vehículos & Malla vial (km) & Vehículos/km \\
\hline 2010 & 400754 & 2403 & 167 \\
\hline 2011 & 428427 & 2419 & 178 \\
\hline 2012 & 448869 & 2435 & 185 \\
\hline 2013 & 453399 & 2450 & 186 \\
\hline 2014 & 469680 & 2466 & 191 \\
\hline 2015 & 514232 & 2482 & 208 \\
\hline 2016 & 543242 & 2497 & 218 \\
\hline 2017 & 588046 & 2513 & 235 \\
\hline 2018 & 642063 & 2529 & 254 \\
\hline 2019 & 677012 & 2544 & 267 \\
\hline 2020 & 721480 & 2560 & 282 \\
\hline
\end{tabular}

Fuente: Arboleda et al. (2012).

En conclusión, Cali hoy tiene problemas de infraestructura en la construcción de vías como también en la recuperación de la malla vial; además, el parque automotor está creciendo vertiginosamente a tasas superiores del 5\% cada 20 años (ceteris paribus). ${ }^{8}$ Por tanto, se debe tener presente que hay serios problemas de congestión y tráfico vehicular. Entonces tomando en cuenta la proyección al año 2021 en lo que significa la reducción de la malla vial y el escenario tan caótico, la respuesta en los próximos años es que el parque automotor deberá desbordarse por encima de la actual infraestructura vial. En consecuencia, aumentará en peores condiciones el problema cotidiano de la congestión y el tráfico vehicular dado que el parque automotor está en pleno crecimiento (figura 7).

Finalmente, durante los años 2016 y 2017 se elaboró el Plan Integral de Movilidad Urbana (PIMU) o Plan Maestro de Movilidad, el cual orientaba la creación e implementación de un sistema integrado de transporte donde todos los elementos de la movilidad (actores, infraestructura, medios de transporte, etc.) se pudieran desarrollar para consolidar las condiciones para la interrelación de los factores económicos, sociales, políticos y culturales (Latorre, 2016, p. 55), apuntando a los esquemas de competitividad que expuso el POT 2014. Sin embargo, en el año 2018 el Concejo Municipal de Santiago de Cali no aprobó el proyecto a causa de dudas técnicas y financieras. ${ }^{9}$ En síntesis, el documento como política pública tampoco resolvía el problema de la congestión vehicular, es más lo acentuaba; además
8 Término del lenguaje económico que significa: manteniendo lo demás constante.

9 Ver: https://www. eltiempo.com/colombia/ cali/el-alcalde-de-caliadoptara-el-plan-integral-de-movilidad-pordecreto-296752 territorios 42 21 


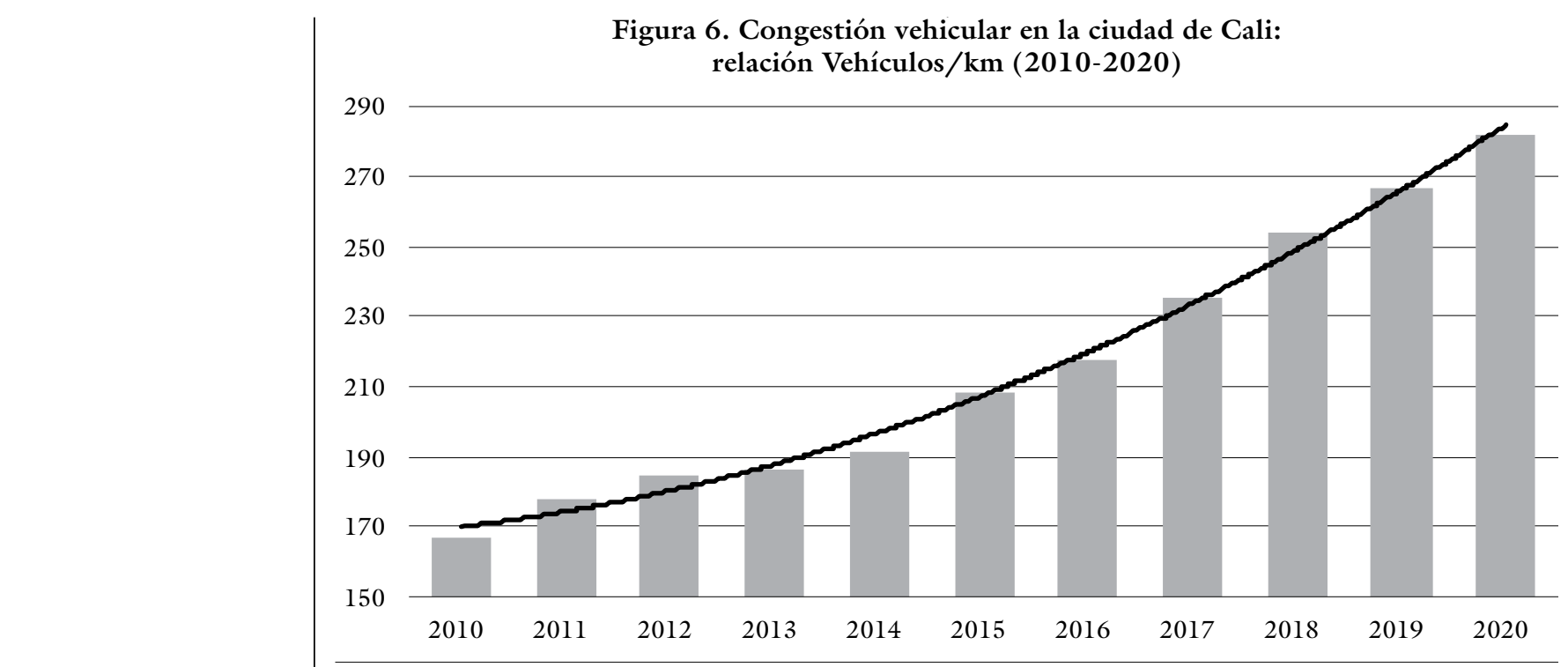

Fuente: a partir de Arboleda et al. (2012).

Figura 7. Proyección porcentual de parque automotor y malla vial (1969-2021)

\section{territarias 42}

Fuente: elaborado a partir de datos de Planeación Municipal. 
los lineamientos de política tenían serias incongruencias con el modelo de ciudad.

\section{Conclusiones}

La congestión ocasionada por tráfico vehicular es un problema cada vez más recurrente de las ciudades a nivel mundial, es más su abordaje no es singular sino más bien plural y responde a un problema institucional donde se articulan categorías o variables que pasan por lo político, lo económico, lo social, lo cultural y la misma herencia histórica. En esta articulación categorial se basó el desarrollo del presente artículo donde la raíz del problema obedece a un contexto complejo dadas las categorías de análisis.

En primer lugar habría que plantear que las ciudades capitales-regionales en Colombia (Barranquilla, Bucaramanga, Medellín, Bogotá y Cali) en lo que se refiere a sus procesos de desarrollo fueron más bien tardíos en relación al contexto de la modernidad. En este aspecto, los efectos de la industrialización fueron los motores que impulsaron el desarrollo territorial.

En segundo lugar, para el caso de la ciudad de Cali, el desarrollo urbano fue un escenario de transición entre el modelo hacendatario hacia el entorno de la industrialización, es decir, desde el siglo XIX hasta 1930. El desarrollo urbano de la ciudad de Cali siempre ha estado demarcado por una elite del poder institucional donde se conjugan terratenientes, empresarios y políticos, quienes definen las trazas del desarrollo urbano. Por ejemplo, la aparición de la electricidad y el alumbrado público siguieron la ruta occidente-oriente desde la colina de San Antonio entre la carrera primera y la carrera octava hasta la calle 25 , donde a partir de la calle 13 empezaron los primeros emplazamientos empresariales e industriales en la ciudad. Posteriormente su desarrollo se prolongó entre las carreras primera y octava hasta la calle 52 .

Asimismo, esta elite del poder definió los límites de la urbanización y su desarrollo físico-urbanístico. Ante este apetito voraz territorial de las elites del poder se construyó la ciudad de Cali: un diseño minimalista que se evidencia hoy en día en la dimensión de sus calles, avenidas, carreras y transversales.

Por ello, la elite siempre ha definido el diseño urbano en correlación a la estructura social, es decir, el territorio urbanizado como urbanizable para los ciudadanos y la periferia para los migrantes pobres excluidos, tal cual como en la polis griega. Desafortunamente esta elite del poder nunca dimensionó a futuro una estructura de ciudad-región acorde con la zaga del desarrollo y las constantes migraciones poblacionales. Más bien los intereses de la elite son rentísticos: aprovechan económicamente el suelo urbano y dejan poco o nada al espacio público, entre estas las vías urbanas de comunicación. Por ello desde aquí inicia la raíz del problema de 
la congestión, dado que la concepción de la comunicación urbana fue minimalista y sin desarrollos a largo plazo.

Ahora, el desarrollo vial de la ciudad de Cali tuvo un hito trascendental e histórico: ser una ciudad-región receptora de flujo poblacional y automotor permanente por ser un paso obligado del transporte al sur del país. Adicionalmente, las vías principales que atraviesan la ciudad de norte a sur no son más que cinco en orden de importancia: Autopista Sur Oriental, Calle $5^{\text {a }}$, Avenida Roosevelt, Avenida Sexta y Avenida Simon Bolívar. Por último, muchas de estas obras de infraestructura vial fueron construidas, rediseñadas o mejoradas para mostrar el desarrollo urbano de Cali con motivo de los VII Juegos Panamericanos de 1971. Por lo tanto, en casi 50 años no ha habido en la ciudad una macroobra estructural de particular importancia como las ya citadas.

A este atraso de infraestructura vial, cabe agregar también que desde finales de la década de los setenta la ciudad tuvo un desarrollo desordenado y desproporcionado en la planicie oriental en lo que se conoce como el Distrito de Aguablanca (el tamaño de este territorio equivale al $40 \%$ de la ciudad). Desde esas épocas hasta hoy, las inversiones públicas se han concentrado en urbanizar lo que anteriormente fue un asentamiento subnormal. Por ello muchas de las obras de infraestructura durante décadas se han canalizado a esta zona.
Por otra parte, en los últimos cuarenta años el desarrollo vial de Cali ha estado centrado en la conectividad intrazonal alrededor de puentes, reparcheo de vías, señalización de calles, instalación de semáforos y pavimentación. En este sentido, los efectos del atraso vial son más que evidentes; además, las obras de comunicación vial se han orientado en función de la estructura de los carriles del sistema de transporte Mío. Así mismo, en los últimos diez años el parque automotor ha estado creciendo a tasas superiores del $2 \%$, hecho que se evidencia en el caos vehicular.

Finalmente, frente a estos hechos de congestión vehicular la acción del Estado con la sociedad es marginal porque no hay políticas públicas claras frente al problema ni se avizoran a corto plazo las grandes obras de infraestructura relevantes ni tampoco el modelo institucional de pico y placa ha logrado reducir los cuellos de botella de congestión vehicular en la ciudad más importante del suroccidente colombiano. Ahora bien, de no resolverse este problema en el mediano plazo muy problamentente impactará socialmente y se desbordará aumentando otros problemas públicos como las tasas de criminalidad en relación a los robos y los asesinatos en las vías de Cali. Este fenómeno galopante reafirma aún más la persistente crisis de ingobernabilidad municipal, como también la ausencia de una gobernanza institucional.

\section{tersitarias 42}




\section{Referencias}

Alcaldía de Santiago de Cali - Departamento Administrativo de Planeación Municipal -DAPM-. (1979). Situación del transporte.

Alcaldía de Santiago de Cali - Departamento Administrativo de Planeación Municipal -DAPM-. (1990). Estudio plan vial y de transporte de la ciudad de Cali. Periodos históricos y transporte en cali.

Alcaldía de Santiago de Cali - Departamento Administrativo de Planeación Municipal -DAPM-. (2000). Plan de ordenamiento territorial de Cali. Documento soporte.

Alcaldía de Santiago de Cali - Departamento Administrativo de Planeación Municipal -DAPM-. (2014). Plan de ordenamiento territorial de Cali. Documento soporte. Cali: Alcaldía de Santiago de Cali.

Aprile-Gniset, J. (1992). La ciudad colombiana: siglos XIX Y XX. Bogotá: Biblioteca del Banco Popular.

Arango, S. (1993). Historia de la arquitectura en Colombia. Bogotá: Universidad Nacional de Colombia.

Arboleda Vélez, G. (1990). Estudio plan vialy de transporte de la ciudad de Cali. Cali: Departamento Administrativo de Planeación Municipal.

Arboleda, M., Aristizabal, I., Parra, I., \& Sabogal, H. (noviembre 2012). Estudio dinámico de la movilidad en la ciudad de Santiago de Cali-Colombia. Ponen- cia presentada en el X Congreso Latinoamericano de Dinámica de Sistemas, Fundación Universidad Argentina de la Empresa, Buenos Aires.

Arboleda, G. \& Rivas, G. (1991). Estudio plan vial y de trasporte de la ciudad de Santiago de Cali. En Departamento Administrativo de Planeación Municipal. Periodos históricos y transporte en Cali. Cali.

Aristóteles. (2001). Política. Libros I y III. Barcelona: Ediciones Folio.

Arroyo Reina, J. (2006). Historia de las Prácticas Empresariales del Valle del Cauca. Cali 1900-1940. Cali: Universidad del Valle.

Banco Interamericano de Desarrollo - BID-. (2016). De ciudades emergentes a ciudades sostenibles. Chile: Ediciones ARQ - Pontificia Universidad Católica de Chile.

Cali, Departamento Administrativo de Planeación Municipal —DAPM-. (2015). Cali en cifras.

Camacho Aranguren, M. (2006a). Emcali en la Historia de Cali. Cali: Editorial Feriva.

Camacho Aranguren, M. (2006b). La encrucijada de los servicios públicos en Cali (1961-1991). Cali: Imprenta Departamental del Valle del Cauca.

Camacol. (2008). El sector de la construcción en Colombia: hechos estilizados y principales determinantes del nivel de actividad. Bogotá. Recuperado de: https://camacol.co/sites/ 


\section{territarias 42}

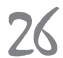

default/files/secciones_internas / EE_Inv20081119101141_0.pdf

Colmenares, G. (1987). La formación de la economía colonial. En: Historia Económica de Colombia. Bogotá: Siglo XXI editores.

Colombia, Departamento Nacional de Planeación. (1972). Las Cuatro Estrategias.

Cuervo González, L. (2004). Desarrollo económico y primacía urbana en América Latina. Una visión históricacomparativa. En A. C. Torres (Comp.) El rostro urbano de América Latina (pp. 77-114). Buenos Aires: Clacso.

Chaparro Valderrama, J. (1998). La Ciudad contemporánea y el proyecto urbano. En Colombia urbana. Una aproximación cultural (pp. 105-132). Bogotá: Universidad Nacional Abierta y a Distancia (UNAD).

Escorcia, J. (1981). La sociedad caleña en la primera en la primera mitad del siglo XIX, en Santiago de Cali 450 años. Cali: Editorial XYZ.

Fainboim Yaker, I. \& Rodríguez Restrepo, C. (2000). El desarrollo de la infraestructura en Colombia en la década de los noventa. CEPAL. Recuperado de https:// repositorio.cepal.org/bitstream/ handle/11362/7532/S2000550_ es.pdf? sequence $=1$ \&isAllowed $=y$

Hurtado, A. (2010). Reseña de Sáenz, J. Elite Politica y Construcciones de Ciudad, Cali 1958-1998. Primera Edición. Universidad Icesi. Cali. Recuperado de http://www.scielo.
org.co/scielo.php?pid=S2011 03242011000200017 \&script $=$ sci $_{-}$ arttext\&tlng=pt

Jaramillo, S. \& Cuervo, L. (1986). La evolución de la dinámica espacial en Colombia. Bogotá: CEDE- Universidad de los Andes.

Jiménez, N. (2005). Desastres por inundaciones y deslizamientos en Cali, 1950 -2000. (Tesis de pregrado, Universidad del Valle, Cali).

Kalmanovitz Krauzer, S. (2015). Breve historia económica de Colombia. Bogotá: Fundación Universidad de Bogotá Jorge Tadeo Lozano.

Latorre Estrada, E. (2016). Movilidad y viabilidad en Cali: una carrera perdida. En A. Guzmán \& E. Rodriguez (Eds.) Percepción y ciudad: análisis de la encuesta del programa Cali cómo Vamos (2005-2014) (pp. 41-66). Cali: Universidad Autónoma de Occidente - ICESI.

Londoño Motta, J. (2011). Path dependence, instituciones y ordenanzas en la configuración del departamento del Valle, 1910-1949. Revista CS, (8), 279-314. Doi: https://doi. org/10.18046/recs.i8.1136

López Acero, H. (2011). Lauchlin Currie y el desarrollo colombiano. Revista Criterio Libre, 9(14), 21-42. Doi: https://doi.org/10.18041/19000642/criteriolibre.2011v9n 14.1229 Martínez Gómez, C. \& Rincón, M. (1997). Tendencias recientes de las migraciones 
internas en Colombia. Desarrollo Urbano en Cifras, (2).

Martínez Toro, P. (2016). La metropolización afectada por la globalización: reflexión epistemológica sobre la nueva revolución urbana. Cuadernos de Geografia-Revista Colombiana de Geografía, 25(2). Doi: 10.15446/rcdg. v25n2.56907

Massiris Cabeza, Á. (2002). Ordenación del territorio en América Latina. Revista Scripta Nova, 6(125).

Mayorga, M. (2013). Espacios de centralidad urbana y redes de infraestructura. (Tesis doctoral, Universitat Politécnica de Catalunya UPC Barcelona TECH).

Melo, J. (2015). Economistas y economía en la Nueva Granada. En: La Economía Colonial de la Nueva Granada. Bogotá: Editorial Banco de la Republica - Fondo de Cultura Económica.

Michels, R. (2001). Los partidos politicos I. Un estudio sociológico de las tendencias oligárquicas de la democracia moderna. Buenos Aires: Amorrortu editores.

Montoya Garay, J. (2013). El sistema urbano colombiano frente a la globalización: reestructuración económica y cambio regional. Cuadernos de Vivienda y Urbanismo, 6(12), 302-320. Recuperado de https://revistas.javeriana. edu.co/index.php/cvyu/article/ view $/ 7038$

Mosquera Torres, G. (2011). Expansión urbana y políticas estatales en Cali. Revista Polis, Observatorio de Politicas Públicas, 8-10.
Mosquera Torres, G. (1989). Procesos de autoconstrucción en Cali. Universidad Nacional de Colombia e Institute of Housing Studies (BIE, Holanda).

Mosquera Torres, G. (1996). Vivienda estatal y desarrollo urbano en Colombia. El caso de Cali. En Corporación Colegio de Villa de Leyva (Ed.) Estado, Ciudad y Vivienda. Urbanismo y Arquitectura de la Vivienda Social en Colombia 19181990 (pp. 187-274). Bogotá: Puntos Suspensivos Editores.

Ordoñez Burbano, L. (1995). Industrias y empresarios pioneros, Cali 1910-1945. Cali: Universidad del Valle.

Palacios, J. \& Moreno, J. (2012). Ciudad MIO: Análisis de los impactos del Sistema de Transporte Integrado Masivo entre los jóvenes universitarios durante el desarrollo de sus actividades en el tiempo libre en Cali. (Tesis de pregrado, Universidad del Valle, Cali).

Pérez, Gerson J. (2007). Historia, geografía y puerto como determinantes de la situación social de Buenaventura. Documentos de Trabajo sobre Economía Regional, (91).

Pérez Fernández, F. (2010). Laboratorios de reconstrucción urbana: Hacia una antropología de la política urbana en Colombia. Revista de Antropologia y Arqueologia (Antipoda), (10). Doi: https://doi.org/10.7440/antipodal 0.2010.04

Prieto Garzón, J. \& Luengas Pinzón, E. (2011). La ley orgánica del ordenamiento territorial como instrumento territarias 42 


\section{territarias 42}

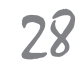

para la integración del ordenamiento territorial y ambiental. Bogotá: Universidad Militar Nueva Granada.

Ramírez Orrego, E. (2011). Valle del Cauca: aspectos de su proceso de configuración regional en el contexto republicano. (Tesis de maestría, Pontificia Universidad Javeriana, Bogotá).

Red de Ciudades Cómo Vamos. (2015). Informe de calidad de vida, comparado de 14 ciudades de Colombia 2011-2013. Boletin, (6). Recuperado de http://redcomovamos.org/ wp-content/uploads/2015/02/ Bolet\%C3\%ADn6_ICV.RedComoVamos_Febrero2015.pdf

Robledo Gómez, Á. \& Rodríguez Santana, P. (2008). Emergencia del sujeto excluido, aproximación genealógica a la no-ciudad en Bogotá. Bogotá: Editorial Pontificia Universidad Javeriana.

Sáenz, J. (2010). Elite politica y construcciones de ciudad, Cali 1958-1998. Cali: Universidad Icesi.

Solano de las Aguas, S. \& Conde Calderón, J. (1993). Elite empresarial y desarrollo industrial en Barranquilla 1875-1930. Barranquilla: Ediciones Uniatlántico.

Tovar Zambrano, B. (1989). La economía colombiana (1886-1922). Nueva Historia de Colombia, 5. Bogotá: Planeta Editores.

Urrea, F. (2011). Transformaciones sociodemográficas y grupos socio-raciales en Cali a lo largo del siglo XX y comienzos del siglo XXI. En Garzón, J. B. Historia del Espacio Urbano de Cali del siglo $X X$ (pp. 101-148). Cali: Universidad del Valle.

Valenzuela, A. (2012). Racionalidad y poder. Las élites en la Ciudad de México, 1876-1940. Revista Iberoamericana, 12(47), 9-27. Doi: http://dx.doi. org/10.18441/ibam.12.2012.47.927

Vallderuten, O. (1999). De ordenamientos, reordenamientos y planificación. El plan de ordenamiento territorial de Cali. Que opinan los urbanistas y planificadores. Revista CITCE: Territorio, Construcción y Espacio, (2).

Varela, E. (2001). Las politicas públicas portuarias en Colombia (1959-1991) Gestación, auge y desplome de la empresa estatal Colpuertos. (Tesis de maestría, Universidad del Valle, Cali).

Vásquez, E. (2001). Historia de Cali en el Siglo XX. Cali: Editorial Artes Gráficas del Valle.

Velásquez, A. \& Jiménez, N. (2004). La gestión de riesgos en el ordenamiento territorial; inundaciones en Cali, la CVC y el fenómeno enso. Recuperado de http://www.osso.org.co/docu/ congresos/2004/A_Velasquez_Articulo_OSSO-UV.pdf

Vernant, J. (2001). El individuo, el amor y la muerte en Grecia. Barcelona: Paidós. Vergara Varela, R. (2005). El desarrollo metropolitano de Cali en la década de los años setenta. (Tesis de pregrado, Universidad del Valle, Cali). 
Vergara Varela, R. (2009). El desarrollo de la estructura urbana entre 1968 y el 2008, un caso de análisis de política pública. (Tesis de maestría, Universidad del Valle, Cali).

Vergara Varela, R. (2012). El desarrollo metropolitano de Cali en la década de los años setenta. Cali: Editorial USC. 